\section{Chemical diversity of essential oils from native populations of Eplingiella fruticosa}

\section{Dennis Crystian Silva ${ }^{1}$, Arie Fitzgerald Blank ${ }^{1}$, Daniela Aparecida de Castro Nizio ${ }^{1}$, Taís Santos Sampaio ${ }^{1}$, Paulo Cesar de Lima Nogueira ${ }^{2}$ and Maria de Fátima Arrigoni-Blank ${ }^{1^{*}}$}

\begin{abstract}
The objective of this work was to analyze the content and the chemical diversity of the essential oil (EO) of 22 Eplingiella fruticosa plants collected in Sergipe, Brazil. EOs were obtained from dry leaves by hydrodistillation and analyzed by GC/MS-FID. The mean EO contents ranged from 0.75 to $1.28 \%$. The compounds found in greater amounts formed two clusters. The first cluster consisted of 15 plants and presented bicyclogermacrene (6.29-16.24\%), spathulenol (7.59-15.23\%), 6-caryophyllene (5.77-12.97\%), and caryophyllene oxide (5.00-11.90\%) as major compounds. The second cluster consisted of seven plants and had 1,8-cineole (8.96-15.51\%), $\alpha$-pinene (5.46-13.77\%), and camphor (4.08-11.40\%) as major compounds. Results indicate chemical variability of the $E O$ among $E$. fruticosa plants from the state of Sergipe. This information may assist in conservation strategies by providing data for investigation of biological activities of EO.
\end{abstract}

Key words: Lamiaceae, medicinal and aromatic plant, hydrodistillation, chemical diversity.

\section{INTRODUCTION}

Eplingiella fruticosa Salzm. ex Benth, ex Hyptis fruticosa is a shrub popularly known as "alecrim-de-vaqueiro". It is distributed along the northeast coast of Brazil, and its leaves are used as an anti-inflammatory. Some studies have demonstrated the antimicrobial and antitumor activities of the essential oil and methanolic extract of $E$. fruticosa. Antinociceptive and larvicidal properties have also been identified in the chemical composition of the essential oil (EO) of this plant (Menezes et al. 2007, Silva et al. 2008), which intensified studies on the chemical characterization, biological properties, and conservation of the species.

The yield and chemical composition of the EO of aromatic plants are often related to climatic factors. In recent years, the chemical diversity of EO of plant species has been studied, enabling the obtainment of relevant information for the definition of strategies for the conservation and use of genotypes in breeding programs (Blank et al. 2015, Costa et al. 2015, Nizio et al. 2015). The knowledge on the distribution of the chemical diversity of $E$. fruticosa and on the factors that promote this distribution may assist in the obtainment of EOs with desirable characteristics.
Crop Breeding and Applied Biotechnology 18: 205-214, 2018 Brazilian Society of Plant Breeding. Printed in Brazil http://dx.doi.org/10.1590/1984$70332018 v 18 n 2 n 29$ 
Authors have reported the presence of the major compounds bicyclogermacrene, 1,8-cineole, and $\beta$-caryophyllene in the EO in studies on the antinociceptive activity (Menezes et al. 2007) and on the larvicide activity (Silva et al. 2008) of $E$. fruticosa. Conversely, studies on phenotypic characterization have identified $\alpha$-pinene, $\beta$-pinene, camphor, and limonene as major compounds in the EO extracted from leaves, flowers, and seeds of E. fruticosa (Franco et al. 2011a, Franco et al. 2011b). However, in these studies, plants were collected in only two locations, and thus, they do not represent all the chemical diversity of the species in the state of Sergipe.

Despite being widely distributed in the Brazilian northeast, no studies related to the chemical diversity of the EO of $E$. fruticosa have been found in the literature. The knowledge on the chemical diversity of the essential oil of native plants of $E$. fruticosa from the state of Sergipe may assist in the definition of conservation strategies of the species and will provide data for research studies on the biological activities of the EO. Thus, the objective of the present study was to analyze the content and the chemical diversity of the essential oil of Eplingiella fruticosa plants native to the state of Sergipe.

\section{MATERIAL AND METHODS}

\section{Plant material}

E. fruticosa plants were collected in 11 municipalities in the state of Sergipe, Northeast Brazil, totaling 22 plants, between August and October 2015, at flowering stage. Table 1 shows the identification and location of the 22 plants collected. Vouchers were deposited in the herbarium (ASE) of the Federal University of Sergipe for species confirmation.

\section{Extraction and chemical characterization of essential oils}

Leaves were dried in forced air circulation oven, at 40 으, for five days. EO was extracted by hydrodistillation in a modified Clevenger apparatus. Dried leaves samples (50g) were distilled for 140 minutes (Ehlert et al. 2006) in triplicate. EOs were collected and stored in amber bottles at $-20^{\circ} \mathrm{C}$ until chemical composition analysis. The following equation was used to calculate the EO content obtained from each sample:

Table 1. Identification and origin of E. fruticosa plants collected in municipalities of the state of Sergipe, Brazil

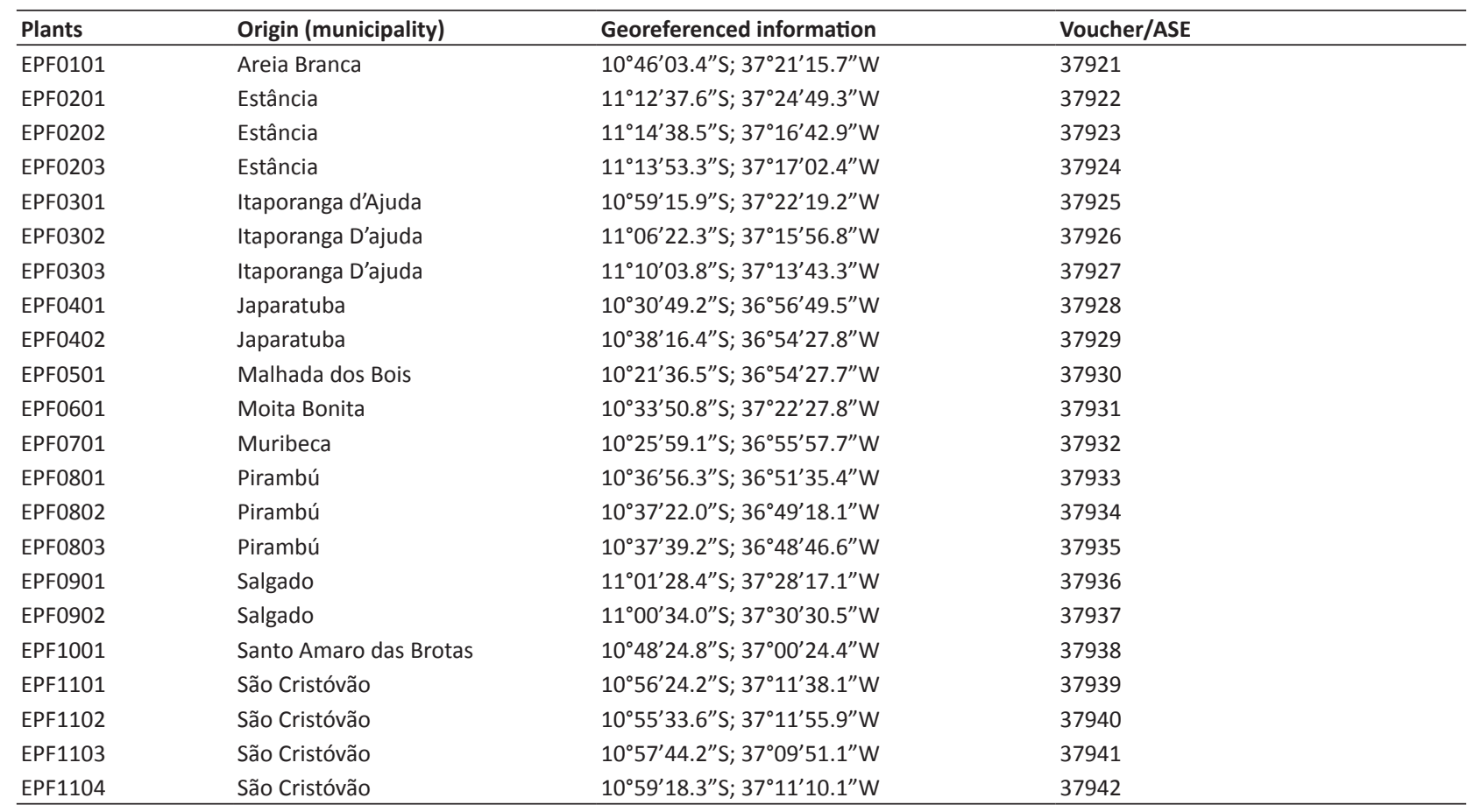




$$
\text { Content }\left(\%, \frac{v}{m}\right)=\left(\frac{\text { Volume of the essential oil extracted from the sample }}{\text { Mass of sample leaves }}\right) \times 100
$$

The chemical composition of E. fruticosa essential oil was analyzed using a GC-MS/FID (QP2010 Ultra, Shimadzu Corporation, Kyoto, Japan) equipped with an autosampler AOC-20i (Shimadzu). Separations were accomplished using an Rtx ${ }^{\circledR}$-5MS Restek fused silica capillary column (5\%-diphenyl-95\%-dimethyl polysiloxane) of $30 \mathrm{~m} \times 0.25 \mathrm{~mm}$ i.d., $0.25 \mathrm{~mm}$ film thickness, at a constant helium (99.999\%) flow rate of $1.2 \mathrm{~mL} \mathrm{~min}^{-1}$. An injection volume of $0.5 \mu \mathrm{L}\left(5 \mathrm{mg} \mathrm{mL}^{-1}\right)$ was employed, with a split ratio of $1: 10$. The oven temperature was programmed from $50^{\circ} \mathrm{C}$ (isothermal for $1.5 \mathrm{~min}$ ), with an increase of $4{ }^{\circ} \mathrm{C} \mathrm{min}^{-1}$, to $200{ }^{\circ} \mathrm{C}$, then $10^{\circ} \mathrm{C} \mathrm{min}^{-1}$ to $250{ }^{\circ} \mathrm{C}$, ending with a $5 \mathrm{~min}$ isothermal at $250{ }^{\circ} \mathrm{C}$.

MS and FID data were simultaneously acquired employing a Detector Splitting System; the split flow ratio was 4:1 (MS:FID). A $0.62 \mathrm{~m} \times 0.15 \mathrm{~mm}$ i.d. restrictor tube (capillary column) was used to connect the splitter to the MS detector; a $0.74 \mathrm{~m} \times 0.22 \mathrm{~mm}$ i.d. restrictor tube was used to connect the splitter to the FID detector. The MS data (total ion chromatogram, TIC) were acquired in the full scan mode $(\mathrm{m} / \mathrm{z}$ of $40-350)$ at a scan rate of 0.3 scan/s using the electron ionization (EI) with electron energy of $70 \mathrm{eV}$. The injector temperature was $250^{\circ} \mathrm{C}$ and the ion-source temperature was $250^{\circ} \mathrm{C}$. The FID temperature was set to $250 \stackrel{\circ}{ } \mathrm{C}$, and the gas supplies for the FID were hydrogen, air, and helium at flow rates of 30,300 , and $30 \mathrm{~mL} \mathrm{~min}^{-1}$, respectively. Quantification of each compound was estimated by FID peak-area normalization (\%). Compound concentrations were calculated from the GC peak areas and arranged in order of GC elution.

\section{Identification of essential oil compounds}

Individual compounds of the essential oil were identified by computerized matching of the acquired mass spectra with those stored in the NIST21, NIST107 and WILEY8 mass spectral library of the GC-MS data system. A mixture of hydrocarbons ( $\mathrm{C} 9 \mathrm{H} 20-\mathrm{C} 19 \mathrm{H} 40)$ was injected under these same conditions, and the compounds were then compared with the spectra obtained with those of the equipment data bank and with the Kovats index, calculated for each component, as previously described (Adams 2007). Retention indices were obtained with equation proposed by Van Den Dool and Kratz (1963).

\section{Statistical analyses}

The experiment was conducted in a completely randomized design, evaluating the content and chemical composition of the essential oils of 22 plants. Three essential oil samples were obtained per plant, corresponding to the replications. The volume of essential oil solution ( $5 \mathrm{mg}$ of essential oil per $\mathrm{mL}$ of ethyl acetate) of each sample injected into the chromatograph was $1.0 \mu \mathrm{L}$.

Data of the essential oil content were subjected to analysis of variance (ANOVA), and the means were compared by the Scott Knott test $(P \leq 0.05)$, using the Sisvar ${ }^{\circledR}$ software.

From the data analysis of the chemical compounds of the EOs, two multivariate analyses were performed: cluster analysis and principal component analysis (PCA), using the Statistica ${ }^{\circledR}$ software. Subsequently, a dissimilarity matrix was constructed based on the chemical constitution of the EOs of each plant, using the Euclidean distance multivariate analysis. The dissimilarity matrix was simplified in dendrogram using the Ward's clustering method. Correlation analysis was carried out between all the chemical compounds of the EO of the sampled plants.

Graphs with the means of chemical compounds and standard deviations for each chemical cluster were constructed with the Graph Pad Prism ${ }^{\circledR}$ software.

\section{RESULTS AND DISCUSSION}

\section{Analysis of essential oil contents}

Similar organoleptic characteristics were observed for the essential oils obtained from different plants. The essential oils presented a yellow-translucent coloration, moderate viscosity, and strong odor.

E. fruticosa plants showed significant differences for essential oil content, and the highest EOs content was observed in plants collected in Itaporanga d'Ajuda: EPF0303 (1.33\%), EPF0301 (1.20\%), and EPF0302 (1.15\%); together with three 


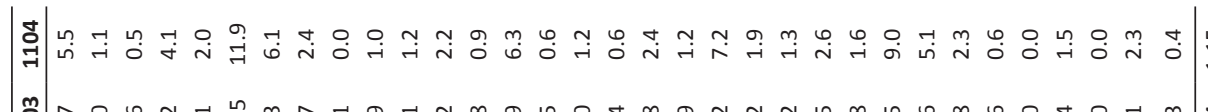

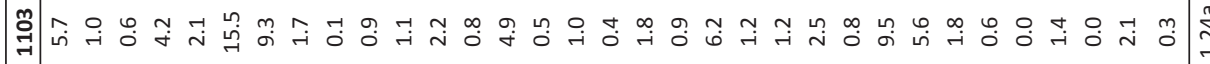

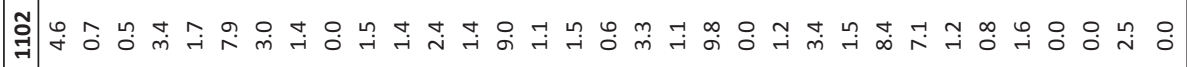
矛於

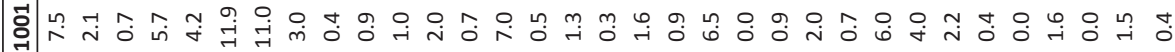
ठิ๊

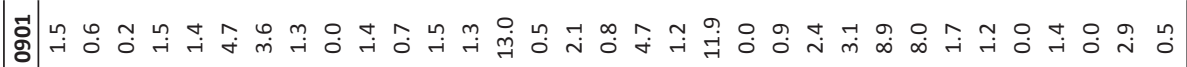

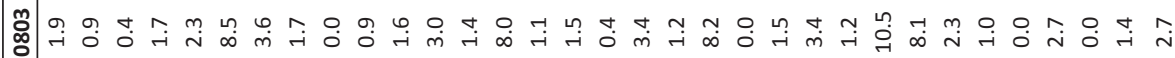

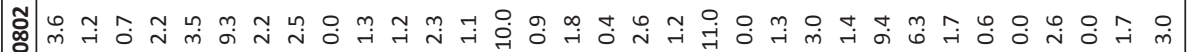

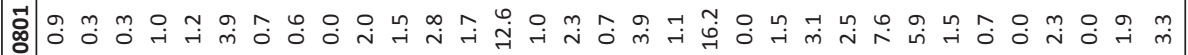
ॠ

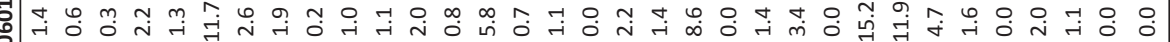

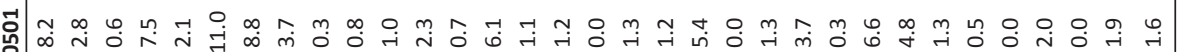

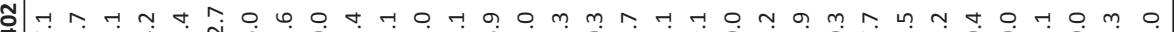
th

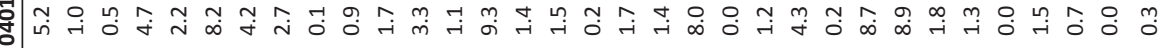

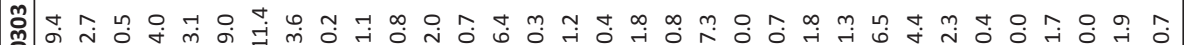

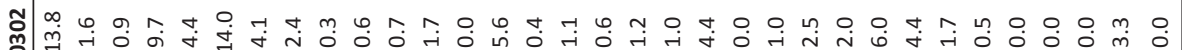
昰 ००

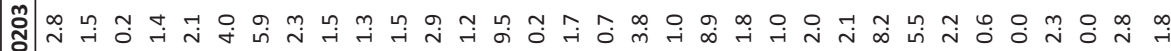
กิ

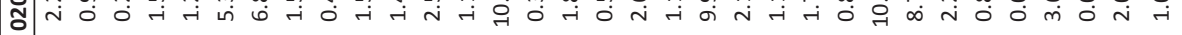

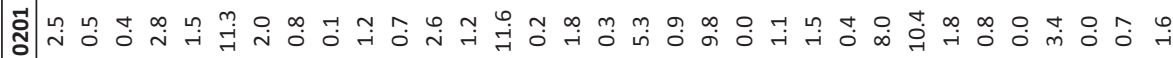

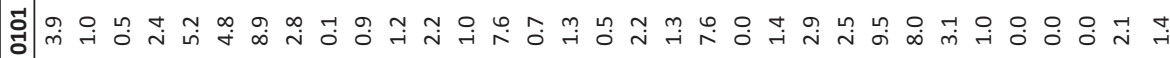

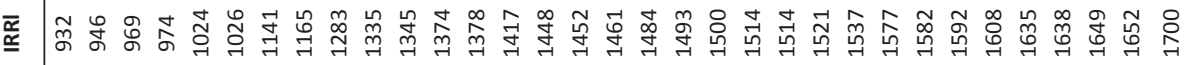

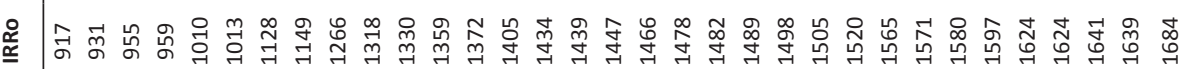


plants from São Cristóvão: EPF1103 (1.24\%), EPF1102 (1.15\%), and EPF1104 (1.15\%); one plant from Japaratuba: EPF0401 (1.20\%); and one plant from Salgado: EPF0901 (1.15\%). The lowest content was observed in two plants collected in Estância (EPF0202 and EPF0203), with means of 0.80 and $0.75 \%$, respectively (Table 2). Results indicate variability among the plants in relation to the EO content of $E$. fruticosa from the state of Sergipe, possibly related to environmental and genetic differences (Regitano Neto et al. 2016).

When evaluating the EO content in Hyptis pectinata, the authors observed no significant differences between the six genotypes studied (mean of 0.5\%) (Arrigoni-Blank et al. 2008). Conversely, for Hyptis marrubioides, variability was observed among the studied genotypes; however, the content obtained did not exceed $0.15 \%$ (Botrel et al. 2009). This scenario is possibly related to the physiological and morphological characteristics intrinsic to the species associated with the environmental characteristics, although both belong to the same family (Lamiaceae).

\section{Analysis of the chemical composition of the essential oils}

The regions where plants were collected have similar characteristics of relief, soil, and average annual temperature. The reliefs of the collection points are predominantly dissected in hills and inter-river tables. The soil is classified as yellow-red podzolic, with coarse texture surface horizon. The annual average temperature ranges from $24^{\circ} \mathrm{C}$ (in Areia Branca, Malhada dos Bois, Moita Bonita, Muribeca, and Salgado) to $26^{\circ} \mathrm{C}$ (in Itaporanga D’Ajuda, Japaratuba, Pirambú, Santo Amaro das Brotas, and São Cristóvão). The annual average rainfall is different between the regions, ranging from $920 \mathrm{~mm}$ in Malhada dos Bois, located in the hinterland of Sergipe, to $1465 \mathrm{~mm}$ in Estância, located in the east mesoregion of Sergipe.

By analyzing the chemical composition of the EO of the $22 \mathrm{E}$. fruticosa plants, 119 compounds were detected. Only 33 compounds were considered in the statistical analyses, and those with value lower than $1 \%$ were discarded (Table 2 ).

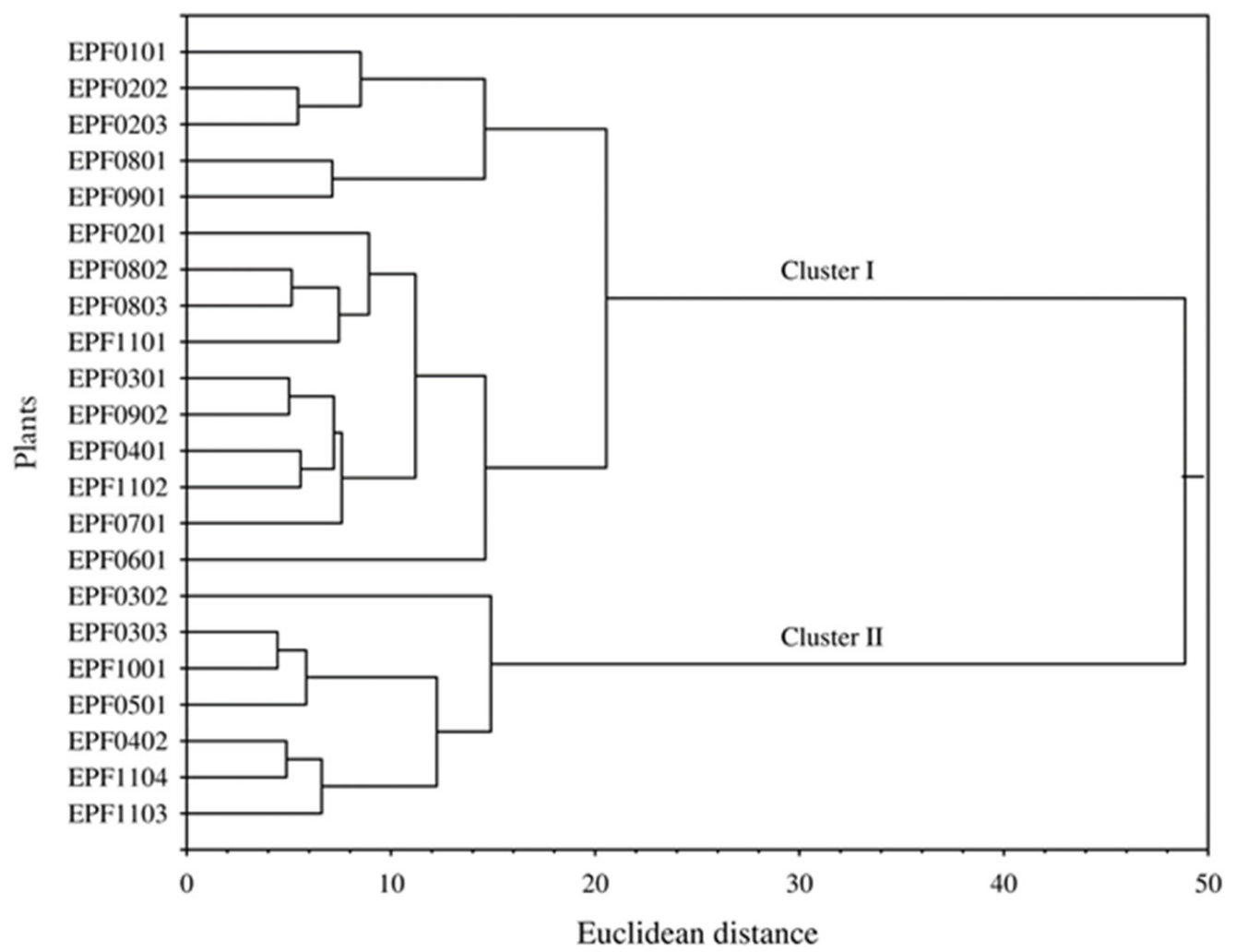

Figure 1. Bidimensional dendrogram representing the similarity of $22 \mathrm{E}$. fruticosa plants to the chemical composition of their essential oils. 
The compounds 1,8-cineole, $\alpha$-pinene, $\beta$-pinene, $\beta$-caryophyllene, bicyclogermacrene, camphor, spathulenol and caryophyllene oxide were found in greater amount, which defined the formation of two clusters, according to the cluster analysis (Figure 1). Cluster I, consisting of 15 plants (EPF101, EPF201, EPF202, EPF203, EPF301, EPF401, EPF601, EPF701, EPF801, EPF802, EPF803, EPF901, EPF902, EPF1101, and EPF1102), had bicyclogermacrene (6.29-16.24\%), spathulenol (7.59-15.23\%), $\beta$-caryophyllene (5.77-12.97\%), and caryophyllene oxide $(5.00-11.90 \%)$ as major compounds.

Cluster II, consisting of seven plants (EPF302, EPF303, EPF402, EPF501, EPF1001, EPF1103 e EPF1104), had 1,8-cineole (8.96-15.51\%), $\alpha$-pinene (5.46-13.77\%), and camphor (4.08-11.40\%) as major compounds (Figure 2).

The compounds bicyclogermacrene, $\beta$-caryophyllene, and 1,8-cineol were also identified as major compounds in several studies with E. fruticosa (Menezes et al. 2007, Silva et al. 2008, Franco et al. 2011a, Franco et al. 2011b), besides spathulenol (Silva et al. 2008), $\alpha$-pinene and camphor (Franco et al. 2011a, Franco et al. 2011b). Caryophyllene oxide had been classified as minor compound in all previous studies with oil of $E$. fruticosa leaves. These variations are possibly related to the influence of the location and the collection period.

Considering that bicyclogermacrene and spathulenol were efficient in phytopathogenic fungi control (Mashigo et al. 2015), and that $\beta$-caryophyllene and caryophyllene oxide were efficient in tick repellency (Ashitani et al. 2015), the EOs of the plants of the first cluster may have potential biological activity and may contribute to other studies, such as those related to pest control. The same occurs to the EOs of the plants of the second cluster, since they present a mean of $12.29 \%$ of 1,8 -cineole and $8.1 \%$ of camphor (Figure 2), and these compounds have already proven their insecticidal activity (Sriramavaratharajan et al. 2016, Tak et al. 2016).

According to the principal component analysis (Figure 3 ), the first principal component represented $31.03 \%$ of the total variation, and was positively related to the compounds $\beta$-cubebene ( $r=0.89)$, bicyclogermacrene ( $r=0.89)$, $\alpha$-humulene ( $r=0.87), \beta$-caryophyllene $(r=0.86)$, germacrene $\mathrm{D}(r=0.84)$, and $\delta$-elemene $(r=0.78)$; and negatively related to the compounds $\alpha$-pinene $(r=-0.86)$, $\beta$-pinene $(r=-0.84)$, camphene $(r=-0.70)$, and 1,8-cineole $(r=-0.70)$. The second principal component represented $18.15 \%$ of the total variation, and was positively related to $\alpha$-cadinol $(r=0.72)$, and negatively related to $\beta$-eudesmol $(r=-0.80)$, trans-muurola-4(14),5-diene ( $r=-0.78)$, humulene epoxide II $(r=-0.75)$, and spathulenol $(r=-0.73)$.
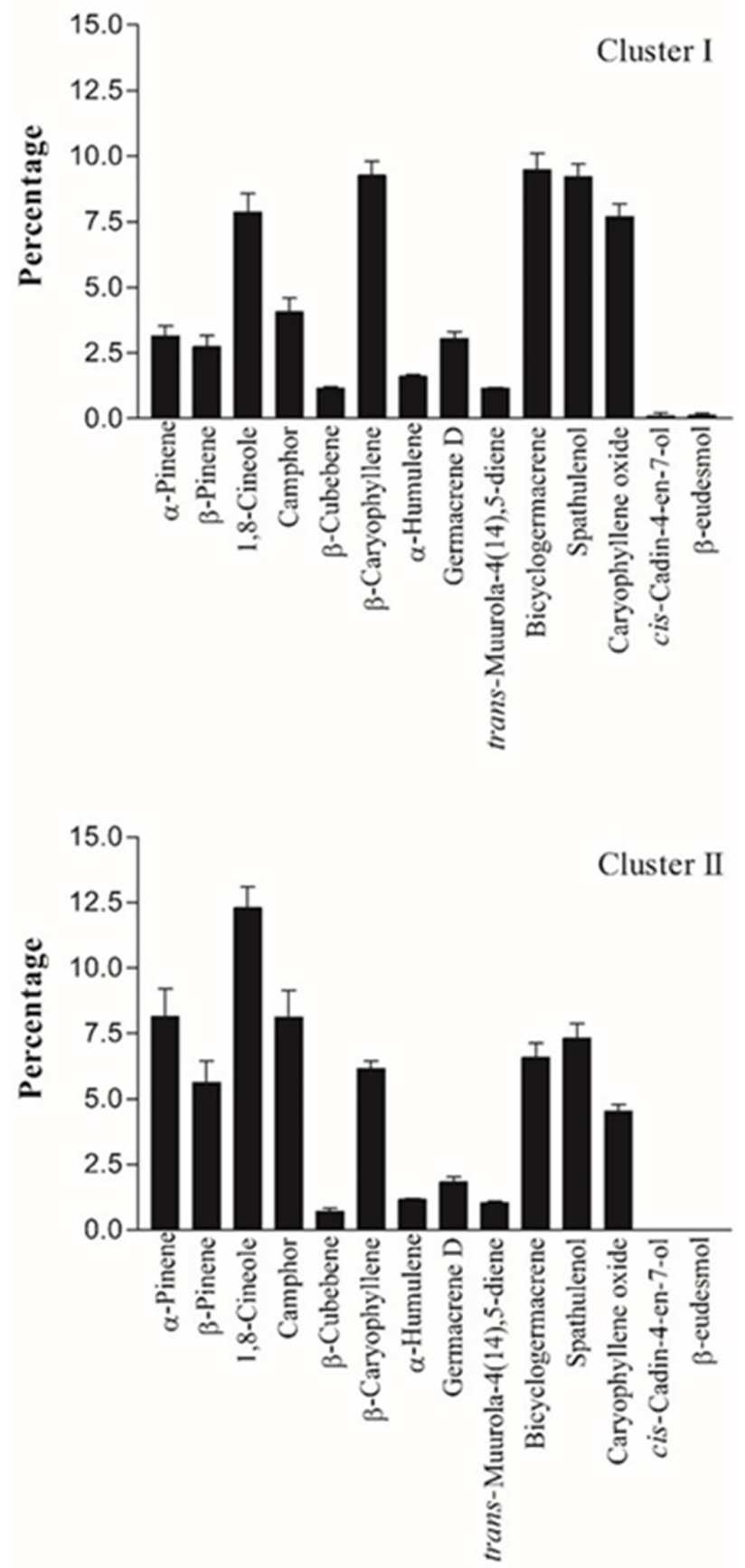

Figure 2. Means of the major chemical compounds of the essential oils of $E$. fruticosa plants, clusters 1 and 2. 


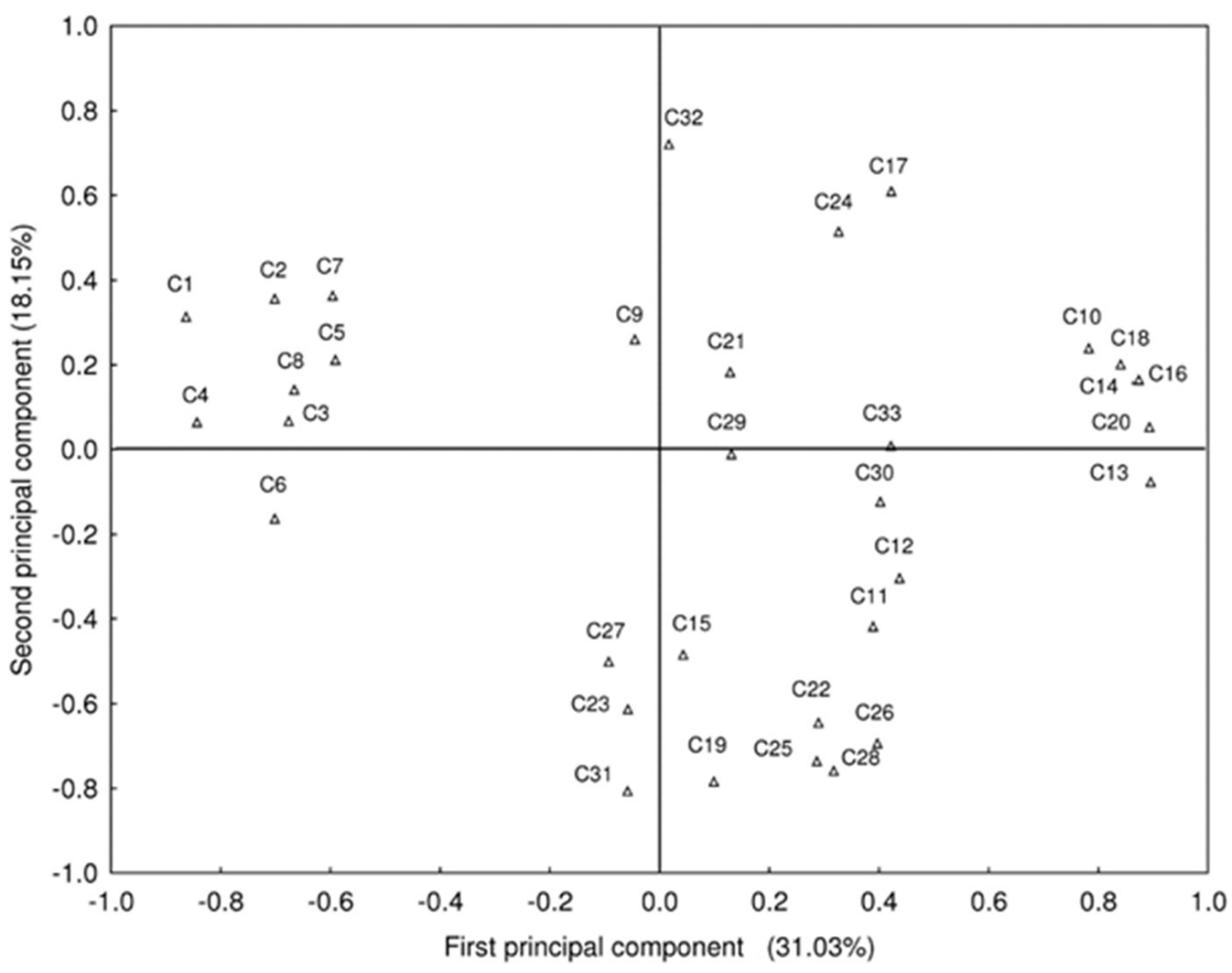

Figure 3. Distribution of the chemical compound of the essential oil from $E$. fruticosa samples in relation to the two principal components through the principal component analysis (PCA). (C1) $\alpha$-pinene, (C2) camphene, (C3) sabinene, (C4) $\beta$-pinene, (C5) limonene, (C6) 1,8-cineole, (C7) camphor, (C8) borneol, (C9) isobornyl acetate, (C10) $\delta$-elemene, (C11) $\alpha$-cubebene, (C12) $\alpha$-copaene, (C13) $\beta$-cubebene, (C14) $\beta$-caryophyllene, (C15) cis-muurola-3,5-diene, (C16) $\alpha$-humulene, (C17) cis-cadina-1(6),4-diene, (C18) germacrene D, (C19) trans-muurol-4(14),5-diene, (C20) bicyclogermacrene, (C21) butylated hydroxytoluene, (C22) cubebol, (23) trans-calamenene, (C24) $\alpha$-cadinene, (C25) spathulenol, (C26) caryophyllene oxide, (C27) epiglobulol, (C28) humulene epoxide II, (C29) cis-cadin-4-en-7-ol, (C30) epi- $\alpha$-cadinol, (C31) $\beta$-eudesmol, (C32) $\alpha$-cadinol, (C33) eudesm-7(11)en-4-ol.

The highest positive correlations were observed between $\alpha$-humulene and $\beta$-caryophyllene $(r=0.98)$; bicyclogermacrene and $\delta$-elemene $(r=0.91) ; \alpha$-cadinene and cis-cadina-1(6),4-diene $(r=0,90)$; trans-calamenene and cis-muurola-3,5diene ( $r=0.89)$; humulene epoxide II and caryophyllene oxide ( $r=0.89) ; \alpha$-pinene and $\beta$-pinene $(r=0.88) ; \alpha$-cadinol and $\alpha$-cadinene $(r=0.84)$; besides bicyclogermacrene and $\alpha$-humulene $(r=0.84), \beta$-cubebene $(r=0.82)$ and $\beta$-caryophyllene $(r=0.82$ ) (Table 3).

The knowledge of the correlations between the chemical compounds in E. fruticosa can be useful in the selection of specific genotypes. For instance, genotypes with high content of $\alpha$-humulene are likely to present high content of $\beta$-caryophyllene. This high positive correlation may be related to the same metabolic pathway in which the compounds present the same precursors (Barros et al. 2009).

Negative correlations were observed between $\beta$-cubebene and $\beta$-pinene $(r=-0,83) ; \beta$-cubebene and $\alpha$-pinene $(r=-$ $0.82) ; 1,8$-cineole and $\alpha$-humulene ( $r=-0.74)$; $\beta$-pinene and biciclogermacrene ( $r=-0.73) ; 1$,8-cineole and $\beta$-caryophyllene $(r=-0.72)$; and $\beta$-pinene and germacrene $\mathrm{D}(r=-0.71)$ (Tabela 3$)$. This negative correlation can also assist the selection of specific genotypes since it allows identifying plants with high content of the first compound to the detriment of the second compound. Negative correlation may be related to different metabolic pathways in which the compounds are synthetized. For instance, farnesyl cation diphosphate is one of the precursors of the pathway of $\beta$-cubebene synthesis and is not on the pathway of $\alpha$-pinene synthesis (Barros et al. 2009). 


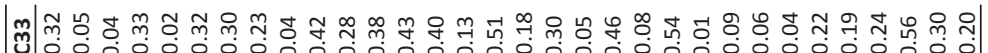

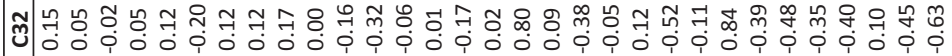

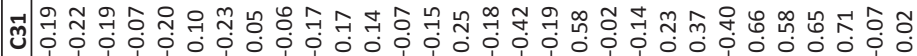

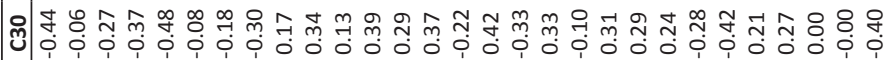

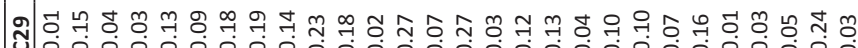

ฟิ

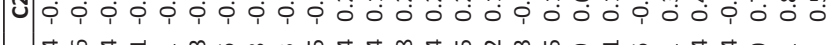

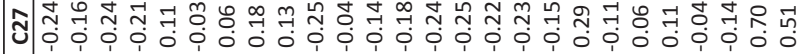

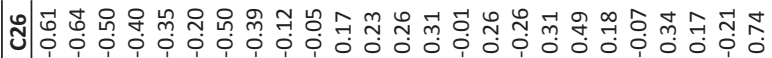

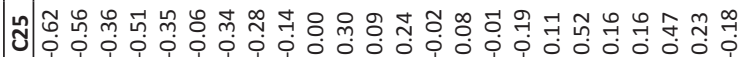

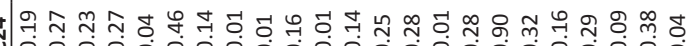

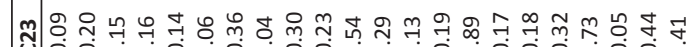

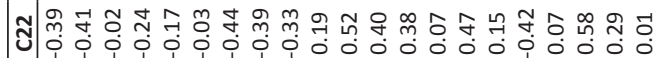

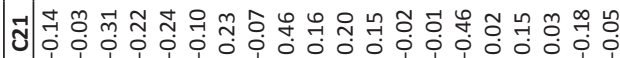

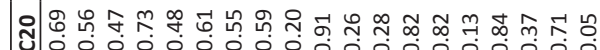

o요 $\infty \circ \infty$ ₹

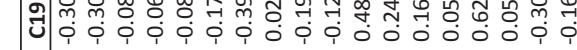

m

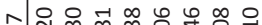

它

U:

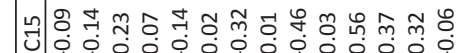

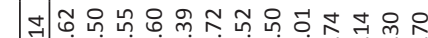

a $\infty m \infty$

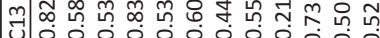

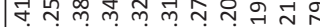

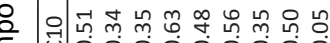

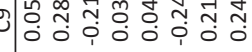

$\infty$ 迄 $\infty$ \&

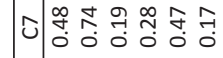

ง)

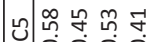

+ $\infty$ 뉴

U.

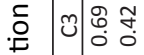

ง 
Despite the variability observed in the composition and phenotypic diversity of the EO of the collected plants, environmental and geographic factors could not be related only to specific chemical clusters since plants collected in the same local/region were clustered separately. Part of this chemical variability is also due to genetic factors since plants collected in neighboring locations and subjected to similar environmental conditions formed different clusters.

Results indicated that: (i) the EO content varied among E. fruticosa plants, (ii) the compounds 1,8-cineole, $\alpha$-pinene, $\beta$-caryophyllene, bicyclogermacrene, camphor, spathulenol and caryophyllene oxide were the major compounds detected in the EO of E. fruticosa plants from the state of Sergipe, and plants of this species were classified into two distinct clusters. Such knowledge will be useful for the establishment of strategies for the conservation and investigation of the potential biological activities of the essential oil of this plant.

\section{ACKNOWLEDGMENTS}

The authors thank CNPq, FAPITEC/SE, CAPES, and FINEP for the financial support for this work.

\section{REFERENCES}

Adams RP (2007) Identification of essential oil components by gas chromatography/mass spectroscopy. Publisher Allured Publishing Corporation, Carol Stream, 804p.

Arrigoni-Blank MF, Antoniolli AR, Caetano LC, Campos DA, Blank AF and Alves PB (2008) Antinociceptive activity of the volatile oils of Hyptis pectinata L. Poit. (Lamiaceae) genotypes. Phytomedicine 15: 334-339.

Ashitani T, Garboui SS, Schubert F, Vongsombath C, Liblikas I, Palsson K and Borg-Karlson A-K (2015) Activity studies of sesquiterpene oxides and sulfides from the plant Hyptis suaveolens (Lamiaceae) and its repellency on Ixodes ricinus (Acari: Ixodidae). Experimental and Applied Acarology 67: 595-606.

Barros FMC, Zambarda EO, Heinzmann BM and Mallmann CA (2009) Variabilidade sazonal e biossíntese de terpenóides presentes no óleo essencial de Lippia alba (Mill.) N. E. Brown (Verbenaceae). Química Nova 32: 861-867.

Blank AF, Camêlo LCA, Arrigoni-Blank MF, Pinheiro JB, Andrade TM, Niculau ES and Alves PB (2015) Chemical diversity in Lippia alba (Mill.) N. E. brown germplasm. The Scientific World Journal 2015: 1-11.

Botrel PP, Pinto JEBP, Figueiredo FC, Bertolucci SKV and Ferri PH (2009) Teor e composição química do óleo essencial de Hyptis marrubioides Epling (Lamiaceae) em diferentes genótipos. Revista Brasileira de Plantas Medicinais 11: 164-169.

Costa AS, Arrigoni-Blank MF, Carvalho Filho JLS, Santana ADD, Santos DA, Alves PB and Blank AF (2015) Chemical diversity in basil (Ocimum sp.) germplasm. The Scientific World Journal 2015: 1-9.

Ehlert PAD, Blank AF, Arrigoni-Blank MF, Paula JWA, Campos DA and Alviano CS (2006) Tempo de hidrodestilação na extração de óleo essencial de sete espécies de plantas medicinais. Revista Brasileira de Plantas Medicinais 8: 79-80.

Franco CRP, Alves PB, Andrade DM, Jesus HCR, Silva EJS, Santos
EAB, Antoniolli AR and Quintans-Júnior LJ (2011a) Essential oil composition and variability in Hyptis fruticosa. Brazilian Journal of Pharmacognosy 21: 24-32.

Franco CRP, Antoniolli ÂR, Guimarães AG, Andrade DM, Jesus HCR, Alves PB, Bannet LE, Patrus AH, Azevedo EG, Queiroz DB, QuintansJúnior LJ and Botelho MA (2011b) Bioassay-guided evaluation of antinociceptive properties and chemical variability of the essential oil of Hyptis fruticosa. Phytotherapy Research 25: 1693-1699.

Mashigo M, Combrinck S, Regnier T, Du Plooy W, Augustyn W and Mokgalaka N (2015) Chemical variations, trichome structure and antifungal activities of essential oils of Helichrysum splendidum from South Africa. South African Journal of Botany 96: 78-84.

Menezes IAC, Marques MS, Santos TC, Dias KS, Silva ABL, Mello ICM, Lisboa ACCD, Alves PB, Cavalcanti SCH, Marçal RM and Antoniolli AR (2007) Antinociceptive effect and acute toxicity of the essential oil of Hyptis fruticosa in mice. Fitoterapia 78: 192-195.

Nizio DAC, Brito FA, Sampaio TS, Melo JO, Silva FLS, Gagliardi PR, ArrigoniBlank MF, Anjos CS, Alves PB, Wisniewski Junior A and Blank AF (2015) Chemical diversity of native populations of Varronia curassavica Jacq. and antifungal activity against Lasiodoplodia theobromae. Industrial Crops and Products 76: 437-448.

Regitano Neto A, Miguel AMRO, Mourad AL, Henriques EA and Alves RMV (2016) Environmental effect on sunflower oil quality. Crop Breeding and Applied Biotechnology 16: 197-204.

Silva WJ, Dória GAA, Maia RT, Nunes RS, Carvalho GA, Blank AF, Alves PB, Marçal RM and Cavalcanti SCH (2008) Effects of essential oils on Aedes aegypti larvae: Alternatives to environmentally safe insecticides. Bioresource Technology 99: 3251-3255.

Sriramavaratharajan V, Stephan J, Sudha V and Murugan R (2016) Leaf essential oil of Cinnamomum agasthyamalayanum from the Western Ghats, India - A new source of camphor. Industrial Crops and Products 86: 259-261.

Tak JH, Jovel E and Isman MB (2016) Comparative and synergistic activity 
of Rosmarinus officinalis L. essential oil constituents against the larvae and an ovarian cell line of the cabbage looper, Trichoplusia ni (Lepidoptera: Noctuidae). Pest Management Science 72: 474-480.
Van Den Dool H and Kratz PD (1963) A generalization of the retention index system including linear temperature programmed gas-liquid partition chromatography. Journal of Chromatography A 11: 463-471. use, distribution, and reproduction in any medium, provided the original work is properly cited. 